Bundesgesundheitsbl $2021 \cdot 64: 1180$ https://doi.org/10.1007/s00103-021-03350-9 Online publiziert: 1. Juli 2021

(c) Der/die Autor(en) 2021

\author{
Hajo Zeeb ${ }^{1,2,5} \cdot$ Iris Pigeot ${ }^{1,2,3} \cdot$ Benjamin Schüz $z^{1,4}$ \\ 'Leibniz WissenschaftsCampus Digital Public Health Bremen, Bremen, Deutschland \\ ${ }^{2}$ Leibniz-Institut für Präventionsforschung und Epidemiologie - BIPS, Bremen, Deutschland \\ ${ }^{3}$ Fachbereich Mathematik und Informatik, Universität Bremen, Bremen, Deutschland \\ ${ }^{4}$ Fachbereich Human- und Gesundheitswissenschaften, Institut für Public Health und Pflegeforschung, \\ Universität Bremen, Bremen, Deutschland \\ ${ }^{5}$ Fachbereich Human- und Gesundheitswissenschaften, Universität Bremen, Bremen, Deutschland
}

\title{
Erratum zu: Digital Public Health - Rasanter technischer Fortschritt, aber viele offene Public-Health-Fragen
}

\author{
Erratum zu: \\ Bundesgesundheitsbl 2020 \\ https://doi.org/10.1007/s00103-020- \\ 03092-0
}

Der Artikel „Digital Public Health - Rasanter technischer Fortschritt, aber viele offene Public-Health-Fragen" von Hajo Zeeb, Iris Pigeot und Benjamin Schüz wurde ursprünglich Online First ohne „Open Access“ auf der Internetplattform des Verlags publiziert. Nach der Veröffentlichung in Bd. 63, Heft 2, pp. 135-136 hatten sich die Autoren für eine „Open Access"-Veröffentlichung entschieden. Das Urheberrecht des Artikels wurde deshalb in (c) The Author(s) 2020 geändert.

\section{Korrespondenzadresse}

Prof. Dr. Hajo Zeeb

Leibniz-Institut für Präventionsforschung und Epidemiologie - BIPS

Achterstr. 30, 28359 Bremen, Deutschland

zeeb@leibniz-bips.de

Funding. Open Access funding enabled and organized by Projekt DEAL.

Open Access. Dieser Artikel wird unter der Creative Commons Namensnennung 4.0 International Lizenz veröffentlicht, welche die Nutzung, Vervielfältigung, Bearbeitung, Verbreitung und Wiedergabe in jeglichem Medium und Format erlaubt, sofern Sie den/die ursprünglichen Autor(en) und die Quelle ordnungsgemäß nennen, einen Link zur Creative Commons Lizenz beifügen und angeben, ob Änderungen vorgenommen wurden.
Die in diesem Artikel enthaltenen Bilder und sonstiges Drittmaterial unterliegen ebenfalls der genannten Creative Commons Lizenz, sofern sich aus der Abbildungslegende nichts anderes ergibt. Sofern das betreffende Material nicht unter der genannten Creative Commons Lizenz steht und die betreffende Handlung nicht nach gesetzlichen Vorschriften erlaubt ist, ist für die oben aufgeführten Weiterverwendungen des Materials die Einwilligung des jeweiligen Rechteinhabers einzuholen.

Weitere Details zur Lizenz entnehmen Sie bitte de Lizenzinformation auf http://creativecommons.org/ licenses/by/4.0/deed.de. 